\title{
Cursos de Administração: a dimensão pública como sujeito excluído
}

\author{
Administration courses: the public dimension as an excluded subject \\ Agatha Justen ${ }^{1}$ \\ Fundação Getulio Vargas / Escola Brasileira de Administração Pública e de Empresas, Rio de Janeiro, RJ - Brasil \\ Claudio Gurgel ${ }^{2}$ \\ Universidade Federal Fluminense / Departamento de Administração, Programa de Pós-Graduação em Administração, \\ Niterói, RJ - Brasil
}

\section{Resumo}

Este artigo analisa a presença dos conhecimentos abrangentes sobre administração pública na formação do administrador de empresas. Considera-se que a expansão do ensino da Administração, no Brasil, deu à formação universitária papel muito relevante no campo profissional e na formação da cidadania. Demonstra-se, também, como, ao longo dos anos, cresceu a importância da esfera pública no âmbito da economia e ampliaram-se as relações entre os setores. Desenvolveram-se associações entre a esfera privada e o Estado, via concessões, parcerias e arranjos públicos não estatais, além daquilo que historicamente já se consolidou, enquanto papel do Estado, como as políticas públicas e o fomento ao desenvolvimento. Nesse ambiente, conhecimentos e éthos públicos se colocam como uma necessidade na formação do administrador de empresas. A partir desse preâmbulo, metodologicamente, foram examinadas as grades curriculares de 16 cursos de graduação das mais importantes instituições de Ensino Superior localizadas em Brasília, Rio de Janeiro e São Paulo, além da análise documental das diretrizes e resoluções do Ministério da Educação (MEC) e do Conselho Nacional de Educação para a área da Administração. Os resultados revelam a pouca atenção para com esses aspectos tão significativos, tanto por parte do MEC como por parte das instituições.

Palavras-chave: Administração de empresas. Administração pública. Curso de Administração.

\begin{abstract}
This article analyzes the presence of comprehensive knowledge on public administration in a business administrator's education. It is believed that the expansion in Administration education, in Brazil, has provided university education with a very significant role in the professional practice and in the promotion of citizenship. It is also shown how, over the years, the importance of the public sphere has grown in the economic domain and the relations between sectors have increased. The associations between the private sector and the State, through grants, partnerships, and non-State public arrangements have been developed, in addition to what has been historically established, as the State's role, such as public policies and the promotion of development. In this environment, public knowledge and ethos are a need regarding a business administrator's education. By means of this preamble, methodologically, the curricula of 16 undergraduate courses of the most significant Higher Education institutions were examined, located in Brasília, Rio de Janeiro, and São Paulo, besides a documentary analysis of the guidelines and resolutions from the Ministry of Education (MEC) and the
\end{abstract}

Artigo submetido em 24 de outubro de 2013 e aceito para publicação em 28 de abril de 2015.

DOI: http://dx.doi.org/10.1590/1679-395112349

${ }^{1}$ Doutoranda em Administração pela Fundação Getulio Vargas (EBAPE/FGV). Endereço: Praia de Botafogo, 190, Botafogo, CEP 22253-900, Rio de Janeiro, RJ - Brasil. E-mail: agatha justen@hotmail.com

2 Professor Associado do Departamento de Administração e do Programa de Pós-Graduação em Administração (PPGAd) da Universidade Federal Fluminense (UFF). Endereço: Rua Mario Santos Braga, 30, $7^{\circ}$ andar - sala 701 - Campus Valonguinho, Centro, CEP 24020-150, Niterói, RJ - Brasil. E-mail: crmgurgel@hotmail.com 
National Council for Education in the Administration Field. The results reveal a poor attention paid to such relevant aspects, both by MEC and the institutions.

Keywords: Business administration. Public administration. Administration course.

\section{Introdução}

O campo da administração pública (AP) tem sido largamente estudado nos anos recentes. A reorganização dessa área nos níveis federal, estadual e municipal, verificada pelo aumento significativo dos concursos públicos para administradores públicos e criação de novas carreiras - como analista e gestor de políticas públicas, de planejamento e orçamento, dentre outros - tem estimulado a recuperação do debate sobre a importância da AP na academia.

Ademais, por parte dos governos e das instâncias político-administrativas do Ensino Superior, tem havido consideráveis estímulos à criação de cursos de graduação e pós-graduação em AP e em Políticas Públicas. Um exemplo desse novo contexto de ampliação do campo de AP na academia foi a edição especial da Temas de Administração Pública (2010), intitulado Panorama dos cursos de Públicas no Brasil, na qual os editores destacam que a edição deve ser vista como comemorativa

[...] do reconhecimento, antes tácito, agora formal, do campo de Públicas como uma formação acadêmica em nível de graduação, com identidade própria. Comemorativa do surgimento de um grande número de novos cursos no último quinquênio, em todas as regiões do país, integrantes desse campo do saber (FONSECA e COELHO, 2010).

Não significa, entretanto, que tais mudanças estejam necessariamente alterando os paradigmas dominantes principalmente a partir dos anos 1990 no Brasil. Especificamente, não podemos afirmar, sem dúvidas, que a lógica de subordinação da AP à administração privada - aquela que identifica a segunda como mais eficaz e mais eficiente; que determina que a privada deve ser o espelho da pública em termos de práticas, de meios e de fins - foi superada. Em face disso, podemos indagar em que medida esses esforços para a reemergência da dimensão pública, como esfera de poder e como objeto acadêmico, têm, de fato, repercutido no âmbito da formação do administrador.

Por esse motivo, propomos, neste artigo, olhar para a relação da AP com a administração de empresas sob ótica distinta. Partindo da ideia de que a AP, pela via da presença historicamente marcante do Estado na economia brasileira, tem profunda importância para o setor privado, o qual, em nenhum momento deixou de se relacionar estreitamente com ela, analisamos o quanto essa relação é reconhecida pelas instituições de Ensino Superior em Administração (IES) e pelo Conselho Nacional de Educação.

Para isso, primeiramente, fazemos a identificação do panorama no qual se encontra a Administração no cenário do Ensino Superior brasileiro. A seguir, caracterizamos histórica e teoricamente a relação da AP com a administração privada no Brasil. Partimos, então, para a pesquisa nas grades curriculares de 16 cursos de graduação em Administração das mais importantes instituições de ensino de três estados: Distrito Federal (Brasília), Rio de Janeiro e São Paulo.

Tendo em conta a importância do Estado e de seus órgãos responsáveis pela educação superior no Brasil, visitamos também o Conselho Nacional de Educação, para examinar como a questão em pauta é tratada normativamente.

Associando os resultados encontrados da pesquisa nas IES com as resoluções do Conselho Nacional de Educação, podemos, finalmente, analisar o fenômeno e tirar conclusões. 
Esses termos gerais da metodologia são detalhados em seção específica, quando procuramos explicar ao leitor os critérios definidos para as categorizações realizadas e os procedimentos adotados para a identificação das informações necessárias.

\section{Contextualização do debate}

A educação, em todos os níveis, tem evidente compromisso com a sociedade e com o mercado. Esse compromisso reúne em um só movimento a formação de cidadãos e profissionais capazes de contribuir com quantidades e qualidades superiores, em todos os planos, fundamentalmente no plano da sociabilidade e no plano da produção de riquezas.

A educação superior brasileira não é diferente. À medida que avançaram o capitalismo e a importância do trabalho produtivo ao longo dos anos, ampliou-se, também, o elenco de formações profissionais. Nesse conjunto de formações, tem-se destacado, especialmente nas décadas recentes, a formação em Administração.

No Brasil, segundo o Ministério da Educação, os cursos de graduação em Administração encontram-se entre os mais numerosos de todo o conjunto de cursos oferecidos. Para sermos mais precisos, em todos os indicadores quantitativos do Ensino Superior brasileiro, os cursos de Administração ou lideram ou estão entre os primeiros do ranking.

O número mais elevado de cursos oferecidos, quando acumulados, está entre os cursos de Formação de Professores, que somam 19,2\% dos cursos de graduação. Não é difícil entender esse fato, uma vez que se trata de uma condição sine qua non para o exercício do magistério nos níveis fundamental e médio. Isso faz com que uma gama considerável de estudantes, das mais diferentes áreas, tenha a Formação de Professor como parte de seu desdobramento profissional. Em rigor, sob esse título está uma subárea e não um curso, considerando a classificação usada pelo Instituto Nacional de Estudos e Pesquisas Educacionais Anísio Teixeira (INEP). Excluídos aqueles cursos consolidados em subárea, olhando-se isoladamente, são os 2.113 cursos de Administração, representando 6,59\% do total ofertado na educação superior brasileira, que reúnem a maior quantidade. Trata-se, ademais, de um crescimento extraordinário, a uma média anual bastante alta, dado que em 2002 existiam, no Brasil, nessa formação, 1.413 cursos (INEP, 2013) e, em 2004, já havia 1.734 cursos (OLIVEIRA e SAUERBRONN, 2007). Essa elevação exponencial tem início em meados dos anos 1990, à medida que, como afirma Fisher, em 1993, havia, no Brasil, apenas cerca de 300 cursos de graduação em Administração (FISHER, 1993).

Afora o número de cursos, a Administração lidera o número de ingressantes, a quantidade de concluintes, a quantidade de vagas oferecidas e o número de inscrições. A Administração era menor apenas na quantidade de matrículas do que os cursos de Direito, cuja posição, perdida em 2010, foi recuperada em 2011. Contudo, até esse indicador tem hoje a Administração à frente, com 10,95\% do total de estudantes matriculados no Brasil, conforme a última Sinopse da Educação Superior publicada até a conclusão deste artigo (INEP, 2013).

A Tabela 1, que se apresenta a seguir, expõe a liderança quantitativa da formação em Administração em todos os dados gerais da graduação da universidade brasileira. A formação em Administração ultrapassou numericamente a formação em Direito e é hoje o curso que oferece a maior quantidade de vagas, que tem o maior volume de matriculados, de inscritos e de ingressantes e que coloca no mercado o maior volume de graduados. Vale dizer que esses números não se referem a cursos de gerenciamento e similares, cujas estatísticas são específicas, e que elevariam consideravelmente esses quantitativos. Aqui consideramos exclusivamente os cursos de Administração, como classificados pelo Ministério da Educação (MEC). 
Tabela 1

Cursos de Administração no conjunto dos cursos de graduação no Brasil em 2013

\begin{tabular}{|l|l|l|l|l|}
\hline \multicolumn{1}{|c|}{ Indicadores } & Total Brasil & \multicolumn{1}{|c|}{ Administração } & \% & $\begin{array}{c}\text { Posição no } \\
\text { ranking }\end{array}$ \\
\hline Número de cursos & 32.049 & 2.113 & 6,59 & 1 \\
\hline Matrículas & 7.305 .977 & 800.114 & 10,95 & 1 \\
\hline Ingressantes em 2013 & 2.742 .950 & 286.251 & 10,43 & 1 \\
\hline Concluintes em 2013 & 991.010 & 116.188 & 11,72 & 1 \\
\hline $\begin{array}{l}\text { Número de vagas } \\
\text { oferecidas }\end{array}$ & 5.068 .142 & 588.251 & 11,6 & 1 \\
\hline Número de inscritos & 13.374 .439 & 1.108 .913 & 8,29 & 1 \\
\hline
\end{tabular}

Fonte: Elaborada pelos autores a partir de INEP, 2013.

As explicações para esse fenômeno estão evidentemente localizadas no mercado e na sociedade. No mercado, uma vez que esse crescimento acompanha o crescimento da oferta de educação superior de âmbito público e privado. Como alguns críticos já chamaram a atenção, os custos de um curso de Administração são inferiores a diversas alternativas e isso pesa na decisão de investimento. É isso que afirma Nicolini (2003, p. 47) a respeito da "evolução desmedida do crescimento da graduação em Administração", citando uma passagem da Comissão de Especialistas de Ensino de Administração, a qual afirma que "a abertura dos cursos apresenta-se vantajosa, uma vez que poderiam ser estruturados sem muitos dispêndios financeiros". No entanto, a despeito do baixo custo, nenhuma decisão de investimento se fará apenas pelo custo da oferta, mas também pela tendência de mercado a constituir uma demanda que o justifique. A sociedade brasileira, no movimento mundial de valorização do mercado, do empreendedor e de outros aspectos da economia, em particular da economia privada, parece ter identificado a formação em Administração como adequada a uma geração que herda empresas e é a principal beneficiária da emergência do Brasil na economia global. Essa emergência, por seu turno, também exerce pressão, uma vez que a ela correspondem exigências de crescimento, de modernização e de eficiência das empresas. Pode-se falar, ainda, da tendência à profissionalização das empresas e até da nova feição das organizações não governamentais (ONG) e do surgimento das Organizações da Sociedade Civil de Interesse Público (OSCIP), como agentes econômicos, interessados em conhecimentos administrativos. Tudo isso destaca a formação em Administração e faz dela uma opção intensa e ininterruptamente procurada.

É nestas condições que os cursos de Administração se apresentam, reunindo, segundo a Sinopse do Ensino Superior brasileiro, mais de oitocentas mil matrículas, número que, no momento em que escrevemos, está possivelmente sendo superado.

Esses cursos são um instrumento poderoso de formação, no sentido que ressaltamos acima: para a sociedade e para o mercado, no plano das relações humanas e no plano da produção de riquezas. É muito influente seu papel para um país que se pretende grande e que anuncia estar em busca da liderança mundial não só entre os produtos internos brutos (PIB), mas, também, entre os índices de desenvolvimento humano (IDH). 
Os projetos pedagógicos desses cursos são, portanto, importantes para a formação do Brasil, para o desempenho de suas organizações privadas e públicas e para a própria visão de mundo e de sociabilidade daqueles que estão e, principalmente, dos que saem das escolas de Administração.

Em que medida esses projetos estão atentos a dimensões da realidade brasileira (e mundial), como, por exemplo, o papel do Estado, o significado da AP e os aspectos relevantes da relação da empresa com esse Estado e essa AP?

O Estado brasileiro é historicamente importante na constituição do Brasil moderno e contemporâneo. O papel exercido, como agente emulador do capitalismo, é registrado nas várias obras que estudam a emergência e o desenvolvimento do sistema. Autores com as mais variadas correntes de pensamento reafirmam o papel do Estado nos fundamentos e nos passos progressivos dados pela economia brasileira. Assim se encontra em Celso Furtado (2009), Bresser-Pereira (2003), Florestan Fernandes (1973), Sérgio Buarque de Holanda (1997), Octávio Ianni (1965), Prado Júnior (1986), Werneck Sodré (1982; 1990) e outros que lhes precederam ou sucederam.

Vale lembrar, ainda, que a economia brasileira contabiliza expressiva participação das despesas públicas, frequentemente superior à crescente carga tributária, estimada em 37,7\% do PIB brasileiro (IBGE, 2015). Ademais, cabe lembrar o peso do Estado brasileiro, por meio de suas agências de fomento econômico, dentre elas, destacadamente, o Banco de Desenvolvimento Econômico e Social (BNDES), ente público que tem frequentado as páginas de jornais e revistas nacionais e estrangeiras, em relatos que tratam de vultosos empréstimos a grupos privados, como em anos passados se pode ler a respeito da tentativa de fusão das grandes redes de supermercado Carrefour e Pão de Açúcar. O BNDES já havia concedido, em 2010, elevado valor aos grupos da indústria de alimentos, Perdigão e Sadia, sempre com taxas de juros especialmente favoráveis, a título de fomentar o desenvolvimento. Tem papel igualmente destacado no estímulo a pequenas e médias empresas com os seus cartões de financiamento.

$\mathrm{Na}$ atualidade, grande parte das parcerias público-privadas (PPP) que viabilizam as obras destinadas aos grandes eventos esportivos e outras obras inseridas no Plano de Aceleração do Crescimento tem percentuais elevados de recursos públicos, seja do BNDES, seja dos próprios orçamentos estatais.

Além do BNDES, há o Banco do Brasil, a Caixa Econômica Federal e outros bancos públicos que mantêm políticas de crédito associadas a políticas públicas econômicas, sociais e ambientais. Nessa lógica, pode-se acrescer a Petrobras, cuja atuação em várias esferas do mercado e da sociedade é mais um testemunho da presença do Estado na economia brasileira.

Pode-se, ainda, destacar as relações históricas entre as grandes empreiteiras de obras, grandes fornecedores e outros setores produtivos privados e o Estado brasileiro, intensamente presentes na atualidade, mas de antiga constituição, haja vista a figura de interpretação criada por Prado Júnior para se referir a esses setores, tratando-os como "capitalismo burocrático". Em comentário a respeito, o autor faz observação bastante ilustrativa do papel do Estado, nessa fração importante da economia brasileira, dizendo que "são essas circunstâncias que farão do governo brasileiro um poderoso instrumento de acumulação capitalista privada que, pelo seu vulto e pelas condições específicas em que se realiza, nitidamente se destaca no conjunto da vida econômica do país" (PRADO JÚNIOR, 1978, p. 124).

O capitalismo burocrático - expressão que designa os grupos econômicos privados, dependentes de demandas do aparelho público - é apenas uma metonímia do que no geral acontece na relação do Estado com o mercado, no Brasil moderno e contemporâneo.

Na mesma direção de Prado Júnior, Florestan Fernandes, em seu citado A revolução burguesa no Brasil, referindo-se à "democracia restrita", mas a identificando como uma constante brasileira, já dizia que "a dominação burguesa não só avançou até o controle total e autocrático do Estado. Ela passou a irradiar-se de "dentro para fora" e de "cima para baixo", por meio de mecanismos estatais de autoproteção e autorrealização" (FERNANDES, 1973, p. 21). 
Há mais o que considerar nessa relevância estratégica do Estado para a sociedade e o mercado brasileiros.

É preciso lembrar, por exemplo, que o processo de burocratização da sociedade global e, nela, da sociedade brasileira, inclusive o mercado, vai acrescentar, à importância econômica do Estado, o peso do direito econômico, que faz da AP uma presença obrigatória em todos os movimentos, atos e fatos da vida social, privada e empresarial.

Hoje, mais que no passado, a AP brasileira está presente legalmente na vida organizacional e social. Ambientes e agentes que operavam, não apenas privadamente, mas com absoluta privacidade, estão submetidos a legislações que foram criadas e são operadas pela AP. É o caso do Direito Ambiental, do Direito do Consumidor, do Direito das Crianças e Adolescentes, do Direito dos Idosos e do Direito de Gênero, todos direta ou indiretamente influentes na vida das organizações e das pessoas.

Tudo isso se torna mais adensado com as privatizações e delegações (concessões), que introduziram no cenário da administração privada um grande espectro de responsabilidades públicas, um aparente paradoxo não compreendido por muitos. As concessões públicas, na telefonia, na distribuição de energia, nos transportes públicos e vias públicas, no fornecimento de água e esgoto, todo esse conjunto de serviços não perdeu sua natureza pública. Ainda que estejam sendo operados por organizações privadas, esses serviços continuam sob o controle estatal, via agências reguladoras, exatamente porque seus traços públicos continuam muito acentuados. Isso exige dos gestores e de seus auxiliares conhecimentos e comportamentos adequados a quem tem o objetivo do lucro, mas está contingenciado pelo caráter público de sua relação com o cliente, cujos direitos vão além do Código do Consumidor e avançam no plano da cidadania.

Entretanto, não só se registram muitas provas do estreito relacionamento entre o público e o privado no âmbito das concessões. Também se observa o mesmo nas privatizações, quando empresas que tiveram suas ações negociadas na Bolsa de Valores continuaram com laços de dependência com o Estado. Os acontecimentos que envolveram a queda de Agnelli, ex-presidente da Companhia Vale do Rio Doce, pelas mãos da presidência da república, são ilustrativos do grau de ingerência a que pode chegar o Estado na esfera privada. Afora eventos extraordinários como o caso da Vale, há ordinariamente a atuação da Comissão de Valores Mobiliários (CVM), e do Conselho Administrativo de Defesa Econômica (Cade), cujas responsabilidades se assemelham às de agência reguladora no âmbito dos negócios privados (BANDEIRA DE MELLO, 2012).

Ademais, não se trata de um fenômeno nacional. A ação do Estado dos países centrais no enfrentamento da crise mais recente foi e ainda está sendo um espetáculo daquilo que se denunciava como intervenção do Estado. Essa ação foi a mais ampla possível, operando da renúncia fiscal à recompra de títulos e ações. Monteiro (2010, p. 1027) chama a atenção para o fato de que "dado o volume de recursos públicos aplicados no salvamento da General Motors (GM), em 2009, a alta direção dessa empresa é sumariamente posta de lado pelo governo Obama".

Ele se referia à operação de resgate da GM realizada no âmbito da crise, ou melhor, do desdobramento generalizado de um problema inicialmente restrito às subprimes e que depois se estendeu a uma crise de todo o sistema. Ali, o governo Obama destacou funcionários públicos para gerir a empresa, até que a ameaça a sua sobrevivência estivesse debelada, como de fato aconteceu.

Tudo, portanto, converge para que essa relação entre o público e o privado seja reconhecida no plano da formação dos gestores brasileiros.

Não é possível desconsiderar a existência e a expansão dos cursos de AP no elenco das graduações brasileiras. Tais cursos têm aparecido, tanto no nível da graduação, quanto no nível de pós-graduação. Esse é um fenômeno que se inscreveu na expansão do Ensino Superior, mas, especialmente, apresentou-se como parte da recomposição do Estado a que os governos mais recentes, não só no Brasil, se dedicaram. 
Contudo, não é exatamente a formação de administradores públicos que queremos destacar e colocar em evidência, neste momento, mas a formação do administrador, tout court. Para maior precisão, estamos nos referindo à administração de empresas, de certo modo predominantemente privada. É nessa formação que, pelos argumentos acima apresentados, julgamos absolutamente necessária a presença do estudo da AP, em seu sentido mais abrangente possível, como decorrência do peso e do significado do Estado e da relação Estado/sociedade para a economia, o mercado e a sociedade brasileiros.

Não seria justo afirmar que as Diretrizes Curriculares em vigor, publicadas pela Resolução n. 4/2005, não concede espaço para propor enfoques públicos nas grades curriculares. Evidentemente há espaço para isso. Entretanto, como teremos oportunidade de ver adiante, tratando do papel do Conselho Nacional de Educação, esse espaço existe apenas pela flexibilidade da resolução. Ela deixa o currículo aberto a todas as possibilidades, dependendo, entretanto, do interesse ou da consciência da necessidade, que possa eventualmente existir.

Em outras palavras, a questão que se apresenta como um problema efetivo é que, na ausência de determinações que explicitem o conteúdo de Públicas como necessário à formação do administrador, a percepção dessa necessidade fica submetida à concepção dos formuladores dos projetos pedagógicos em cada instituição de ensino.

Pior que isso: quando os próprios formuladores dos projetos pedagógicos não percebem essa necessidade, o preenchimento dos conhecimentos acerca da gestão pública passa a ser dependente do interesse autônomo do estudante. Além disso, dependerá também de sua disposição em descobrir onde se oferece para ele o acesso a esse conhecimento e como pode ele, na inscrição em disciplinas, viabilizar esse acesso.

Verifica-se, portanto, um problema que se reveste de certa gravidade, porque parece escapar à percepção dos responsáveis por encontrar uma solução.

Por isso, o objetivo deste artigo - avaliar a presença dos conhecimentos abrangentes da AP na formação do administrador de empresas - nos exige investigar as propostas pedagógicas dos cursos de graduação em administração de empresas. Para isso, analisaremos as grades curriculares de tais cursos nos três mais importantes centros de decisão, planejamento e produção da economia brasileira - Distrito Federal (Brasília), Rio de Janeiro e São Paulo.

\section{Procedimentos metodológicos}

Para alcançar o objetivo, que é verificar o quanto a AP, marcante na economia e na sociedade brasileiras, está presente nos cursos de formação em administração de empresas no Brasil, optamos por realizar pesquisa documental, em consulta às legislações referentes ao ensino de Administração no Brasil, e às grades curriculares de 16 cursos de graduação das principais instituições de ensino localizadas nos três estados citados acima. Primeiramente, a consulta foi realizada nos sites eletrônicos das instituições. As consultas foram realizadas no primeiro semestre de 2013, atualizadas no primeiro semestre de 2014 e em janeiro de 2015.

Estamos procurando os sinais de reconhecimento ou não, por parte desses cursos, de que a AP é parte integrante e relevante da formação do administrador, ainda que ele se coloque inteiramente voltado para a gestão de organizações privadas.

Entendemos que esse reconhecimento pode se revelar por variados meios. Dentre eles, existem as atividades extracurriculares que podem colocar em evidência conteúdos e conhecimentos relativos a qualquer esfera, seja pública ou privada. 
No entanto, consideramos que, a despeito da eficácia da informalidade para o aprendizado e das atividades suplementares como veículo para a aquisição de conhecimentos, a expressão mais comprometida de um projeto pedagógico - e de uma concepção de ensino e formação - se materializa na grade curricular do curso.

Portanto, nosso olhar recairá sobre as grades curriculares, entendendo-as como a forma mais bem definida e explícita de uma proposta pedagógica.

Na delimitação da amostra, escolhemos e visitamos os sites das principais instituições de Ensino Superior do Rio de Janeiro, São Paulo e Brasília, observando suas escolas de Administração e verificando as grades curriculares dos seus cursos, tomando como referência final o ano de 2015.

Categorizamos como conteúdos de Administração Pública aqueles que presumidamente fazem parte de disciplinas que versam de modo abrangente sobre os negócios públicos, não necessariamente se anunciando como Administração Pública ou Gestão Pública. Essas disciplinas, assim anunciadas, foram tomadas como tal. Entretanto, também foram considerados conteúdos abrangentes de AP as disciplinas denominadas Governo e Administração no Brasil (UnB) ou Estado e Administração Pública (UERJ). Em outra categoria, tratada como disciplinas Correlatas, classificamos disciplinas específicas ou pontuais, tais como Direito Tributário, Direito Trabalhista, Finanças Públicas, Políticas Públicas, dentre outras. Desse modo, abrimos o leque de possibilidades, aumentando o número de eventos possíveis de caracterizar a presença da AP nos cursos pesquisados.

Quanto ao espaço da amostra, no primeiro caso, Rio de Janeiro, levamos em conta o histórico e a herança da ex-capital federal, onde ainda se encontram grandes organizações públicas federais, além das estaduais e municipais. Nos dois outros casos, elegemos São Paulo pelo seu peso geral, no plano empresarial e estatal, e Brasília, pela concentração de órgãos públicos. Estas escolhas consideram as sinalizações das dimensões pública e privada, isoladamente e entre si, que esses ambientes oferecem. Em outras palavras, estamos investigando o problema em centros cujo passado e presente das empresas tem frequente e significativo relacionamento com a esfera pública.

Quando visitamos as Grades Curriculares, fizemos a distinção entre as disciplinas gerais de Administração Pública e as disciplinas Correlatas, como já dissemos acima. Resta dizer que essa distinção decorre do fato de que as disciplinas gerais de Administração Pública oferecem a leitura ampla capaz de introduzir e chamar a atenção do estudante para esse campo de trabalho, de possibilidades e de responsabilidades, enquanto administrador privado e enquanto cidadão.

As disciplinas Correlatas abordam pontos específicos da Administração, tais como as legislações tributária e trabalhista ou ainda finanças públicas, como ilustramos em passagem anterior, cujos focos, por mais abertos que possam ser, não cobrem a diversidade, nem oferecem todos os aspectos éticos, políticos e sociais que as disciplinas gerais de Administração Pública tendem a oferecer e que pesam na formação do administrador de empresas.

Ainda tratando das Grades Curriculares, destacamos as disciplinas Obrigatórias e excluímos as Eletivas ou Optativas, tendo em conta que estas são objeto de tratamentos efetivamente diferentes, tanto por parte da gestão dos cursos, como por parte dos estudantes. A condição de disciplina obrigatória demonstra que o projeto pedagógico do curso a considera necessária à formação - sine qua non. O mesmo não se pode dizer de uma disciplina eletiva, a qual, como diz o próprio nome, fica a critério dos estudantes cursarem-na ou não.

Finalmente, cabe dizer que a quantidade de cursos pesquisados corresponde a instituições expressivas que atuam nos referidos estados. Grandes instituições como Fundação Getulio Vargas (FGV) e Pontifícia Universidade Católica (PUC) e as instituições federais e estaduais tiveram seus cursos pesquisados. 


\section{A exclusão da Administração Pública}

Tivemos, na Introdução, a oportunidade de apresentar, em breve descrição, o significado do Estado e da AP para o mercado e a sociedade brasileira. Desde os anos 1930, quando o desenvolvimentismo foi assumido pelo Estado brasileiro como estratégia econômica, até os anos 2000, quando as crises se explicitaram e os planos de "aceleração de crescimento" foram aprovados e implementados, as empresas e os cidadãos sabem que, para o bem ou para o mal, a AP faz parte da nossa vida diária e das nossas projeções de futuro.

Passado e presente, entretanto, não foram suficientes para tirar do ostracismo a AP e a relação Estado/sociedade, que estão insistentemente ausentes da maioria dos projetos pedagógicos que oferecem formação ao administrador brasileiro. As mais importantes escolas de Administração do Brasil, ou incluem de forma subsidiária, ou não incluem disciplinas relacionadas à AP.

Tomando-se o caso do Estado do Rio de Janeiro, já referido como um dos mais importantes centros de AP do país, senão o mais importante, afora Brasília, capital administrativa do Brasil, pode-se observar no Quadro 1 que as grades curriculares das mais influentes instituições acadêmicas - Escola Brasileira de Administração Pública e de Empresas da Fundação Getulio Vargas (EBAPE/FGV), Universidade Federal Fluminense (UFF), Universidade do Estado do Rio de Janeiro (UERJ), Universidade Federal do Rio de Janeiro (UFRJ), Pontifícia Universidade Católica do Rio de Janeiro (PUC-RJ) e Instituto Brasileiro de Mercado de Capitais (Ibmec) - dão pouca atenção ao Estado, ao governo e as suas relações com as empresas e a sociedade.

Verificando-se por dentro das Grades Curriculares, como se fez para a elaboração da Tabela 2, é possível avaliar mais a fundo a baixa conexão entre as duas modalidades de gestão.

A EBAPE/FGV, em sua grade curricular com 48 disciplinas obrigatórias, registra apenas uma disciplina, Introdução à Administração Pública, com conteúdo voltado para a esfera pública; a Faculdade de Administração e Ciências Contábeis, da UFF, na grade de seu curso de Administração, onde se registram 33 disciplinas obrigatórias, apenas duas, Administração Pública e Finanças Públicas, são explicitamente dirigidas ao estudo da função do Estado. Vale dizer que a segunda é uma disciplina de conteúdo específico. Na UERJ, o curso de Administração tem, em sua grade curricular de 35 disciplinas obrigatórias, além de Estado e Administração Pública, as disciplinas de Legislação Tributária e Legislação Social, destas três apenas a primeira de caráter amplo. Na grade curricular do curso de graduação em Administração da UFRJ, a maior universidade pública do Brasil, encontram-se 40 disciplinas obrigatórias, sem que se observe uma única destinada ao estudo da Administração Pública, nem em sentido específico, nem em sentido lato; o mesmo acontece entre as 35 disciplinas obrigatórias do curso de Administração do Ibmec. Não há qualquer disciplina de Pública na formação do administrador de empresas dessa instituição, a despeito do peso de organizações públicas como o Banco do Brasil e Petrobras, além das já lembradas agências de fomento, no ambiente do mercado de capitais. Sem esquecer que é esse ambiente a razão de ser da CVM. O mesmo se poderia dizer do curso de Administração da PUC-RJ, caso não considerássemos pertinente à gestão pública a disciplina de Legislação Social, uma disciplina correlata, dentre as 39 disciplinas obrigatórias da grade curricular, oferecida aos seus estudantes de administração de empresas.

Em São Paulo, examinadas as principais ofertas - Universidade de Campinas (Unicamp), Escola de Administração de Empresas da Fundação Getulio Vargas (EAESP/FGV), Universidade de São Paulo (USP), Universidade Federal de São Paulo (Unifesp), Instituto de Ensino e Pesquisa (Insper), Mackenzie e Universidade de São Carlos (UFSCar) - encontramos um quadro mais acentuado da ausência da AP na formação dos administradores. Quase todas as Escolas pesquisadas, com exceção de uma, não oferecem em seus cursos de Administração qualquer disciplina que, abrangendo a AP como um todo, venha a compor a formação do administrador. A EAESP/FGV possui um curso de Administração de Empresas e um curso de Administração Pública - apresentando elencos de disciplinas específicos para cada um deles. Diferentemente dos demais cursos pesquisados, o que se pode considerar disponível estaria no elenco de Públicas, não integrando o curso de Administração de Empresas, obrigatoriamente. Entre as Correlatas, a EAESP/FGV oferece, como integrante do curso de Administração de Empresas, com 46 disciplinas obrigatórias, as 
disciplinas de Direito Tributário e Direito Trabalhista. A Unicamp, a USP e a PUC-SP, oferecem disciplinas Correlatas. O Insper não oferece qualquer conhecimento estruturado sobre a AP; Mackenzie e UFSCar disponibilizam, cada uma, apenas uma Correlata: Direito Trabalhista e Instituições de Direito, respectivamente. É especialmente curioso que no centro econômico mais rico e dinâmico do Brasil a importância do diálogo privado-público não seja considerado pelas escolas de Administração, a despeito do volume de recursos que envolvem essa relação na prática das empresas e do governo paulista.

Como exceção, a Unifesp trabalha com uma disciplina de Administração Pública e três correlatas, Direito Trabalhista e Previdenciário, Instituições de Direito e Direito Tributário.

Brasília, onde a proximidade com o cotidiano dos três poderes e da AP sugere maior atenção para a importância do estudo da AP, acaba reproduzindo o mesmo problema. A única instituição que oferece disciplinas de Pública no rol de suas obrigatórias é a Universidade Católica de Brasília (UCB) - uma geral, Administração Pública, e uma correlata, Instituições de Direito Público e Privado. A Universidade de Brasília (UnB) oferece apenas uma disciplina Correlata - Instituições de Direito Público e Privado - e nenhuma disciplina geral. A terceira Escola pesquisada em Brasília, o Centro Universitário do Distrito Federal (UDF), não apresenta em sua grade de disciplinas qualquer conteúdo relacionado com o Estado ou com o governo.

Quadro 1

Disciplinas obrigatórias de Administração Pública e correlatas em cursos de Administração de Empresas. São Paulo, Distrito Federal e Rio de Janeiro, 2015.

\begin{tabular}{|c|c|c|}
\hline Cursos/instituições & Administração pública & Correlatas \\
\hline \multirow{3}{*}{$\begin{array}{l}\text { Gestão de Empresas } \\
\text { (Unicamp) }\end{array}$} & & Empresas e Políticas Governamentais \\
\hline & & Direito Tributário \\
\hline & & $\begin{array}{l}\text { Direito Trabalhista } \\
\text { Instituições de Direito }\end{array}$ \\
\hline \multirow{2}{*}{ Adm. de Empresas (EAESP) } & & Direito Tributário \\
\hline & & Direito Trabalhista \\
\hline \multirow[b]{2}{*}{ Administração (USP) } & & Legislação Tributária \\
\hline & & $\begin{array}{l}\text { Direito do Trabalho } \\
\text { Instituições de Direito }\end{array}$ \\
\hline Administração (PUC-SP) & & Instituições de Direito Público e Privado \\
\hline \multicolumn{3}{|l|}{ Administração (Insper) } \\
\hline $\begin{array}{l}\text { Administração (Mackenzie- } \\
\text { SP) }\end{array}$ & & $\begin{array}{l}\text { Direito Trabalhista } \\
\text { Planejamento Tributário }\end{array}$ \\
\hline
\end{tabular}


Cont. Quadro 1

\begin{tabular}{|c|c|c|}
\hline Cursos/instituições & Administração pública & Correlatas \\
\hline \multirow[t]{2}{*}{ Administração (UFSCar) } & & Instituições de Direito \\
\hline & & Instituições de Direito Público e Privado \\
\hline Administração (Unifesp) & & Legislação Trabalhista e Previdenciária \\
\hline Administração (UnB) & & Instituições de Direito Público e Privado \\
\hline \multirow[t]{2}{*}{ Administração (UCB) } & Administração Pública & Instituições de Direito Público e Privado \\
\hline & & $\begin{array}{l}\text { Planejamento Tributário } \\
\text { Legislação Trabalhista }\end{array}$ \\
\hline \multicolumn{3}{|l|}{ Administração (UDF) } \\
\hline Administração (EBAPE/FGV) & $\begin{array}{l}\text { Introdução à } \\
\text { Administração Pública }\end{array}$ & \\
\hline Administração (UFF) & Administração Pública & Finanças Públicas \\
\hline \multirow[t]{2}{*}{$\begin{array}{l}\text { Administração de Empresas } \\
\text { (UERJ) }\end{array}$} & $\begin{array}{l}\text { Estado e Administração } \\
\text { Pública }\end{array}$ & Legislação Tributária \\
\hline & & Legislação Social \\
\hline Administração (UFRJ) & & Gerência Tributária \\
\hline Administração (PUC-RJ) & & $\begin{array}{l}\text { Legislação Social } \\
\text { Direito comercial e Tributário }\end{array}$ \\
\hline Administração (IBMEC) & & Administração Tributária \\
\hline
\end{tabular}

Fonte: Elaborado pelos autores. 
Tabela 2

Presença da Administração Pública e disciplinas correlatas nos cursos de Administração. 2015.

\begin{tabular}{|c|c|c|c|c|c|}
\hline Cursos/instituições & $\begin{array}{l}\text { Disciplinas } \\
\text { obrigatórias }\end{array}$ & Administração & Correlatas & \multicolumn{2}{|c|}{$\%$ ap cor } \\
\hline $\begin{array}{l}\text { Gestão de Empresas } \\
\text { (Unicamp) }\end{array}$ & 46 & 0 & 4 & 0,0 & 8,7 \\
\hline $\begin{array}{l}\text { Administração de } \\
\text { Empresas (EAESP/FGV) }\end{array}$ & 42 & 0 & 2 & 0,0 & 4,8 \\
\hline Administração (USP) & 52 & 0 & 3 & 0,0 & 5,8 \\
\hline Administração (PUC-SP) & 52 & 0 & 1 & 0,0 & 1,9 \\
\hline Administração (Insper) & 30 & 0 & 0 & 0,0 & 0,0 \\
\hline $\begin{array}{l}\text { Administração } \\
\text { (Mackenzie-SP) }\end{array}$ & 51 & 0 & 2 & 0,0 & 3,9 \\
\hline Administração (UFSCar) & 42 & 0 & 1 & 0,0 & 2,4 \\
\hline Administração (Unifesp) & 44 & 0 & 3 & 0,0 & 6,8 \\
\hline Administração (UnB) & 22 & 0 & 1 & 0,0 & 4,5 \\
\hline Administração (UCB) & 34 & 1 & 3 & 2,9 & 8,8 \\
\hline Administração (UDF) & 36 & 0 & 0 & 0,0 & 0,0 \\
\hline $\begin{array}{l}\text { Administração } \\
\text { (EBAPE/FGV) }\end{array}$ & 46 & 1 & 0 & 2,2 & 0,0 \\
\hline Administração (UFF) & 33 & 1 & 1 & 3,0 & 3,0 \\
\hline $\begin{array}{l}\text { Administração de } \\
\text { Empresas (UERJ) }\end{array}$ & 35 & 1 & 2 & 2,9 & 5,7 \\
\hline Administração (UFRJ) & 40 & 0 & 1 & 0,0 & 2,5 \\
\hline Administração (PUC-RJ) & 39 & 0 & 2 & 0,0 & 5,1 \\
\hline Administração (IBMEC) & 35 & 0 & 1 & 0,0 & 2,8 \\
\hline
\end{tabular}

Fonte: Elaborada pelos autores. 


\section{O papel do Conselho Nacional de Educação}

Um segundo aspecto se apresenta na discussão que estamos fazendo. Referimo-nos às indicações da competência do Conselho Nacional de Educação, em particular da Câmara de Educação Superior, em relação aos cursos de Administração. O Conselho Nacional de Educação é composto de duas Câmaras, a Câmara de Educação Básica e a Câmara de Educação Superior, tendo esta última Câmara a atribuição de "deliberar sobre as diretrizes curriculares propostas pelo Ministério da Educação e do Desporto, para os cursos de graduação", como se lê na Lei n. 9.131/1995. A Câmara de Educação Superior é, portanto, a responsável pelas indicações que têm servido de parâmetro para os projetos pedagógicos dos cursos superiores de graduação e, nesse caso, igualmente para os cursos de administração de empresas.

Essa composição do Conselho Nacional de Educação já estava presente na Lei n. 2.024/1961, que instituía as Diretrizes e Base da Educação, no Brasil, onde já constavam as duas Câmaras e suas atribuições, inclusive aquela que diz respeito à educação superior e aos currículos. Essa é a razão pela qual, antes da Lei n. 9.131/1995, a Câmara de Educação Superior já tinha anunciado as suas diretrizes curriculares para os cursos de administração de empresas.

Essas diretrizes são encontradas na Resolução n. 2/1993, em seu capítulo $1^{\circ}$, que chega a listar 17 disciplinas do Currículo Mínimo:

a) Formação básica e instrumental: Economia, Direito, Matemática, Estatística, Contabilidade, Filosofia, Psicologia, Sociologia e Informática;

b) Formação profissional: Teorias da Administração, Administração Mercadológica, Administração da Produção, Administração de Recursos Humanos, Administração Financeira e Orçamentária, Administração de Materiais e Patrimoniais, Administração de Sistemas de Informação e Organização, Sistemas e Métodos.

Em 2005, essa Resolução n. 2/1993 foi revogada em favor da Resolução n. 4/2005, cujo teor não explicita disciplinas, mas, sim, o que denomina de conteúdos: conteúdos de formação básica, conteúdos de formação profissional, conteúdos de estudos quantitativos e suas tecnologias e conteúdos de formação complementar. Em detalhes, a Resolução n. 4/2005 dispõe sobre os conteúdos em seu art. $5^{\circ}$, a saber:

Art. $5^{\circ}$ Os cursos de graduação em Administração deverão contemplar, em seus projetos pedagógicos e em sua organização curricular, conteúdos que revelem inter-relações com a realidade nacional e internacional, segundo uma perspectiva histórica e contextualizada de sua aplicabilidade no âmbito das organizações e do meio através da utilização de tecnologias inovadoras e que atendam aos seguintes campos interligados de formação:

I - Conteúdos de Formação Básica: relacionados com estudos antropológicos, sociológicos, filosóficos, psicológicos, ético-profissionais, políticos, comportamentais, econômicos e contábeis, bem como os relacionados com as tecnologias da comunicação e da informação e das ciências jurídicas;

II - Conteúdos de Formação Profissional: relacionados com as áreas específicas, envolvendo teorias da administração e das organizações e a administração de recursos humanos, mercado e marketing, materiais, produção e logística, financeira e orçamentária, sistemas de informações, planejamento estratégico e serviços;

III - Conteúdos de Estudos Quantitativos e suas Tecnologias: abrangendo pesquisa operacional, teoria dos jogos, modelos matemáticos e estatísticos e aplicação de tecnologias que contribuam para a definição e utilização de estratégias e procedimentos inerentes à administração; e 
IV - Conteúdos de Formação Complementar: estudos opcionais de caráter transversal e interdisciplinar para o enriquecimento do perfil do formando.

Esses conteúdos apontam aos organizadores dos cursos o que se constitui em conhecimentos necessários a oferecer, no ensino, e a buscar, no estudo e na pesquisa, de docentes e discentes, dos cursos de Administração.

Como se constituem em referência oficial, são indicações que exercem evidente determinação no momento em que se coloca a elaboração da proposta pedagógica ou se procede à revisão de algum projeto já existente. Portanto, agravando a miopia, aquelas formulações de currículo básico para o curso de Administração apresentadas, em 1993, pelo Conselho Federal de Educação, e mais recentemente aquelas instituídas em 2005, pelo mesmo Conselho, excluem qualquer alusão à gestão pública. Vale dizer que, em rigor, não era de se esperar que isso acontecesse, tratando-se de órgãos da AP brasileira, integrantes do Ministério da Educação. Entretanto, efetivamente aconteceu e permanece acontecendo.

Em 1993, a diretriz para o currículo básico, com 17 disciplinas, a que já fizemos referência e listamos em página anterior, não apontava uma única disciplina destinada ao estudo da $\mathrm{AP}$, menos ainda da relação Estado/sociedade. Ainda que se possa dizer tratar-se de um currículo mínimo, percebe-se pela listagem das disciplinas que houve, da parte do policy-maker e/ou legislador, a preocupação em reunir disciplinas que, de fato, oferecem um núcleo de conhecimentos necessários à formação de um administrador. Não se trata de uma lista ilustrativa ou sugestiva. Com aquela listagem pretendeu o CNE responder à pergunta sobre qual conhecimento é absolutamente necessário; isto é, o que minimamente deve fazer parte do currículo pleno do administrador, sine qua non. Portanto, a ausência de disciplinas relacionadas com AP, não existindo sequer uma, de caráter geral, é uma indicação muito forte de que esse não é um conteúdo que os responsáveis pelo currículo mínimo consideraram, naquela ocasião, necessário à formação do administrador de empresas.

A mudança empreendida pela Resolução n. 4/2005 amplia a flexibilidade da organização curricular, uma vez que não indica disciplinas, mas apenas cita algumas como referência e exemplo do conteúdo em questão. Contudo, dois aspectos acabam por produzir o mesmo efeito da resolução anterior, em relação à AP. Em primeiro lugar, em nenhum momento a nova resolução se refere à relação Estado/sociedade ou algo parecido, que insinue algum conteúdo dessa natureza. Em segundo lugar, ao exemplificar com disciplinas que estão listadas na Resolução n. 2/1993, induz os autores dos projetos pedagógicos a reproduzirem as disciplinas ali apontadas e, assim, reproduzirem igualmente os acertos e os erros.

Desse modo, em relação à AP, a Resolução n. 4/2005 não responde ao problema - ainda que se possa dizer, com razão, que a flexibilização que promove autoriza os formuladores dos projetos pedagógicos a irem além e introduzirem no campo do conteúdo de formação básica ou profissional conhecimentos relativos à gestão dos negócios públicos.

O fato que agora constatamos é que, mesmo com essa possibilidade, o setor público está excluído ou minimizado nos mais importantes cursos que formam os administradores de empresa em centros com expressivo histórico de relação Estado/empresa - Rio de Janeiro, São Paulo e Brasília.

Algumas análises realizadas por pesquisadores que estudaram a formação em Administração ajudam-nos a compreender melhor o fenômeno que identificamos neste artigo. Nicolini (2003), por exemplo, quando estuda o processo de constituição dos cursos de Administração no Brasil, chega à conclusão de que a influência da lógica estadunidense, com seu forte viés tecnicista, que serviu de referência às experiências iniciais, ainda hoje permanece nas resoluções do Conselho Nacional de Educação e na prática das instituições de ensino. Mais especificamente, permanece a desconexão das grades curriculares com a realidade, de forma que "cursos caminham separadamente do mundo, como se dele não dependessem. Não há uma colaboração estreita entre a universidade e a sociedade. [...] Os conteúdos enfaticamente técnicos são predominantes no processo de formação do administrador" (NICOLINI, 2003, p. 51). 
Pacheco (2003), por outro lado, atribui à própria área de AP a responsabilidade pelos empecilhos à institucionalização da disciplina enquanto campo de conhecimento autônomo. Seus argumentos são polêmicos e questionáveis, porém a autora destaca um aspecto que parece relevante: a comunidade acadêmica de AP é pequena no Brasil, porque "são poucos os programas de pós-graduação stricto sensu existentes, e o fato de serem justapostos aos programas de business no sistema de pós-graduação acaba reforçando o (auto)isolamento e a identidade difusa" (PACHECO, 2003, p. 69). Ou seja, seguindo um ciclo vicioso, como são poucos os mestres e doutores em AP, sua presença nas instituições de ensino é baixa, quando não é nula. Se as formações em Administração, como constatamos, reproduzem a exclusão da AP como campo de saber relevante, o que teremos será a continuação dessa reprodução, bem como a pouca ou nula presença de especialistas em AP para alterar esse quadro.

A pequena distinção entre administração de empresas e administração pública percebida pelas instituições que regulam a pós-graduação stricto sensu no Brasil - Coordenação de Aperfeiçoamento de Pessoal de Nível Superior (Capes) e Conselho Nacional de Desenvolvimento Científico e Tecnológico (CNPq) - agrava consideravelmente o problema, de forma que leva muitos a crer que a AP é a simples aplicação das técnicas e procedimentos da administração privada no setor público. Por esse motivo, para que as características singulares à área de AP sejam reconhecidas, Pacheco (2003, p. 70) propõe que "a área de administração pública deveria discutir sua desvinculação da área 'Administração e Turismo', no sistema de avaliação da Capes, passando a se vincular junto aos programas de ciência política e políticas públicas”.

Não é preciso dizer que, com advento do discurso que, nas palavras de Child (1993, p. 17), "consiste en llevar los principios de la administración privada a la gerencia del Estado" essa exclusão se acentuou e adquiriu justificativa.

Cresceu consideravelmente a convicção de que os conhecimentos disponíveis no acervo da administração de empresas, entendido no plano da gestão privada, podem ser transferidos sem adequações para a gestão pública. Em outras palavras, significa afirmar que os conteúdos que dizem respeito ao Estado e sua relação com a sociedade teriam se tornado realmente dispensáveis, uma vez que, a rigor, o que se coloca em pauta não é sua consideração, mas sua superação, em favor de uma gestão que se supõe um modelo universal, dotado de ferramentas substantivas, aplicáveis a quaisquer circunstâncias, conforme observou Kettl (2003).

A reforma do Estado brasileiro e o pensamento dominante na academia, em particular nos anos 1990, consolidaram esse desprezo, apesar das evidências de que o Estado e sua administração, a cada privatização ou delegação, tornavam-se cada vez mais objetos a conhecer.

Sim, porque, nessa nova situação, criada com a reforma, quando muitos serviços públicos são geridos pela "administração gerencial", inevitavelmente há aspectos relacionados à cidadania que devem ser levados em conta. Na gestão das concessões e dos novos arranjos públicos - organização social ou PPP, por exemplo estão presentes os elementos que Bozeman (2007, p. 13, tradução nossa) destaca em seu conceito de valor público:

A society's "public values" are those providing normative consensus about (a) the rights, benefits, and prerogatives to which citizens should (and should not) be entitled; (b) the obligations of citizens to society, the state, and one another; and (c) the principles on which governments and policies should be based ${ }^{3}$.

Entretanto, ainda assim, não chegou ao ambiente da educação o reconhecimento de que a desatenção para com a AP representa um extremismo ideológico ou ignorância acadêmica incompatível com a realidade

\footnotetext{
${ }^{3}$ Tradução livre: Valores públicos de uma sociedade são consensos normativos sobre: (a) direitos, benefícios e prerrogativas às quais os cidadãos fazem ou não jus; (b) as obrigações dos cidadãos para com a sociedade, para com o Estado e entre Estado e sociedade e (c) os princípios sob os quais devem ser baseadas a administração e as políticas públicas (Bozeman, 2007, p. 13).
} 
brasileira e mundial, seja da economia, seja da sociedade ou da administração das organizações, simplesmente.

Mais adiante, a partir dos anos 2000, e em particular após a crise de 2008, que já se configurava bem anteriormente para alguns, o Estado passou a ser destacado em sua importância. Na verdade, na prática dos governos, como se demonstrou pela sua presteza para com as necessidades do mercado, ao longo de todos esses anos, a presença do Estado jamais se havia perdido. O fato é que a onda de Estado mínimo que marcou as duas décadas finais do século XX tornou-se menor e, em certos países, deu lugar a uma evidente revisão.

A literatura sobre a AP cresceu, nas editoras e livrarias brasileiras, novos cursos dessa área foram anunciados, vários concursos públicos foram realizados nos diferentes níveis de governo, indicando a reestruturação do aparelho público. Esse fenômeno de redescoberta do público evidentemente reflete uma inflexão mais realista do que aquela que predominava sob o comando do "fundamentalismo liberal" para relembrar a advertência de Soros (2008).

O impacto das políticas anticíclicas, as reformas do Estado, os debates e proposições acerca dos limites da democracia representativa, as demandas crescentes da sociedade, agora tocadas por problemas ambientais e novos direitos - do consumidor, das crianças e adolescentes, dos idosos e de gênero - o treinamento e desenvolvimento de quadros para gerir esse contínuo e crescente complexo aparelho do Estado, todo esse conjunto de aspectos e fatores recolocaram a AP como um sujeito da vida social e profissional.

A AP, como formação específica, passado um período de letargia, obteve um realento, para usar a expressão de Coelho, Olenscki e Celso (2011, p. 1714-1715), no artigo em que recuperam a trajetória do ensino da AP, dos tempos iniciais da EBAP/FGV, aos tempos mais recentes, passando pelo esvaziamento dos anos 1980, em grande medida estimulado pelo ambiente de descrédito do Estado e do pressuposto de que "Estado bom é Estado mínimo".

Segundo os autores,

[...] pode-se afirmar que a EAESP/FGV, Unesp e EG-FJP (Escola de Governo da Fundação João Pinheiro) são as IES (Instituições de Ensino Superior) que mantiveram vivo o ensino de graduação em Administração Pública no país [...] referenciando o (re)surgimento de bacharelados em AP e correlatos a partir do final dos anos 1990 e início dos anos 2000 (COELHO, OLENSCKI e CELSO, p. 1729).

A retomada das escolas de negócios públicos, vale dizer, ocorrida mundialmente, deveria estimular a aproximação entre os dois planos de estudo. No entanto, a observação das grades curriculares não parece sinalizar nessa direção. Cabe observar ainda que, como se pode ler no quadro 1 e na tabela 2, são as instituições privadas aquelas marcantemente refratárias ao diálogo privado-público. Isso talvez se explique pelo traço fundamentalista liberal criticado pelo magnata e investidor George Soros, que, justificando seu sucesso, apesar de mergulhado nos papéis e ações, carteira de risco e cirandas financeiras, não perdeu o senso de realidade.

\section{Conclusão}

A pesquisa que ora apresentamos serviu para traçar um panorama dos cursos de graduação em Administração nos principais estados em termos de relevância administrativa, no que concerne à relação entre as dimensões privada e pública. Os resultados encontrados demonstram que há um problema na base da formação em Administração, o qual desconsidera elementos históricos da constituição do Estado e do setor privado no Brasil e no mundo. 
A expansão das escolas de Administração, lato sensu, e particularmente das escolas de Administração de Empresas, é um aspecto que se destaca no ambiente da educação superior no Brasil. Impulsionados pelas facilidades na implantação, em parte pelos baixos custos de instalação e funcionamento, e também pela perspectiva de demanda, os agentes privados e públicos da educação investiram no lançamento de cursos de Administração no Brasil.

A expansão, que se verifica a partir dos anos 1970, deve-se também a um processo de amadurecimento da economia brasileira, cujo crescimento e modernização vão requerer cada vez mais a profissionalização da gestão, seja do aparelho público, seja das empresas privadas.

A ideia de uma burocracia privada competente e profissional, a concepção de que uma empresa só se consolida ao superar seu caráter familiar, o estímulo ao empreendedorismo, a entrada das ONG e OSCIP no cenário dos negócios - estas e outras leituras científicas e ideológicas do mundo organizacional, valorizaram a formação do administrador e despertaram a demanda latente, transformando o pequeno número de cursos dos anos 1960 em quantidade expressiva no atual período e com perspectivas de crescimento ainda maior.

Os cursos de Administração de Empresas se multiplicam, ano a ano, e superaram a casa das 2.000 ofertas, entre instituições públicas e privadas.

Os cursos se tornaram importantes veículos de formação profissional e de cidadania. É com eles que uma juventude cujo número está em um milhão de matriculados e inscritos aprende o que fazer, como fazer e por que fazer. Portanto, é neles que a nova geração de gestores obtém os conhecimentos do que são as melhores práticas, em todos os sentidos: inclusive éticos, sociais e políticos.

De outra parte, superada a fase de descrédito pela qual passou, no bojo do descrédito geral das instituições públicas, o Estado brasileiro continuou a manter importante papel no desenvolvimento econômico e o potencializou nos últimos 20 anos. Seu desempenho no enfrentamento da histórica e dolorosa inflação brasileira e mais proximamente da crise que ainda abala as grandes economias, credenciou-o. A despeito de tantas acusações e críticas, particularmente à ineficácia de sua ação nos campos da segurança, da educação, da saúde e do combate à corrupção, o fato é que há hoje um reconhecimento de que o Estado é um importante e às vezes decisivo parceiro.

Não bastassem as ações referidas, no controle da inflação e na administração da crise, a economia brasileira há muito depende da atuação do Estado e isso se acentuou com a reforma do aparelho público, realizada nos anos 1990. A relação que as empresas privadas e o setor privado, em sentido amplo, mantém com a administração pública brasileira não é mais restrita ao "capitalismo burocrático" a que Caio Prado Júnior se referia. Uma vasta gama de atividades foi transferida do público para o setor privado - energia, telefonia, saneamento, transporte, mineração etc. - ampliou-se a esfera do que, na linguagem da reforma, se definiu como nível competitivo - saúde, educação, comunicação, cultura etc. - instituíram-se as PPP, expandiram-se as concessões e começam a vingar as organizações sociais e outros arranjos públicos não estatais, onde pontificam associações privadas.

Tudo isso significa gestão e éthos públicos, na medida em que são atividades e serviços destinados ao público ou, quando não, em estreita vinculação com o aparelho público.

Destacamos, portanto, a necessidade de que a formação do administrador de empresas conte com conhecimentos de gestão pública, de preferência, aqueles conhecimentos que possam oferecer uma visão ampla das características específicas e das possibilidades da esfera pública, seja para o trato de negócios, parcerias, contratos, fornecimentos, seja para a condução eticamente adequada desses próprios negócios.

Não estamos enfatizando conhecimentos específicos, que evidentemente são importantes, porque eles respondem principalmente às exigências legais que se colocam sobre as empresas. Tributos, legislação ambiental e trabalhista, por exemplo, fazem parte de um acervo de conhecimentos técnicos específicos que podem ser supridos com a contratação de assessorias e consultorias. 
Referimo-nos a conhecimentos abrangentes que, como já dissemos, proporcionam um saber profundo, porque relacionado, totalizado e revelador das inúmeras nuances da gestão pública, dando também ao administrador privado o mapa de possibilidades da relação privado-público.

No caso das delegações empreendidas, quando as organizações sociais, as concessões, as permissões e as PPP passam a responder por serviços públicos, mais do que o mapa das possibilidades, o estudo da AP é o caminho necessário para a apreensão do significado e de como lidar com o valor público e seus constitutivos. Esses são conhecimentos indispensáveis para alguém que estará gerindo organização e cuja clientela pode ir além da condição de consumidor e se colocar como cidadão com direitos e benefícios. Para não falar das inúmeras relações possíveis entre empresa e Estado, a que o administrador precisa responder na gerência de sua organização.

Há, portanto, um diálogo a ser desenvolvido entre o privado e o público, para que os negócios de ambos os setores possam evoluir de modo eficiente e efetivo.

A pesquisa que fizemos com 16 cursos de Administração de Empresas, nos principais centros de negócios públicos e privados do Brasil, demonstrou que esse diálogo desejável não está acontecendo da forma como seria adequado. Muitos administradores de empresa estão saindo dos seus cursos desconhecendo a AP. Nos dois sentidos da palavra desconhecer: aquele sentido que diz respeito ao ensino/aprendizagem e aquele outro sentido, talvez mais prejudicial, que reforça a leitura reducionista estimulada pelo conceito de Estado mínimo e por uma especial visão superestimada das ferramentas de gerência.

Percebemos que o problema já se inicia pelos próprios atos normativos do MEC, cuja norma em vigor, a Resolução n. 4/2005, tal qual aquela anterior, revogada, a Resolução n. 2/1993, não dedica qualquer palavra a essa óbvia necessidade de que os projetos pedagógicos contemplem o diálogo das duas esferas de negócios: a pública e a privada.

Certamente que, acima da responsabilidade dos formuladores dos projetos pedagógicos das Instituições de Ensino Superior, localiza-se essa surpreendente omissão do Conselho Nacional de Educação, cuja Câmara especializada tem todas as condições para perceber que, se não no passado, o que é duvidoso dizer, seguramente no presente é mais que necessário desenvolver a relação entre administradores privados e públicos, desde sua formação.

Vale dizer que a repercussão desse diálogo, quando a atual distância for superada, certamente não ficará no plano técnico, científico e funcional. Proporcionar contatos com a noção do público e o convívio entre estudantes das duas esferas de preocupação com certeza extrapolará seus efeitos para dimensões da responsabilidade social das empresas, com consequências muito positivas sobre as relações sociais de trabalho e as relações em sociedade, em sua acepção mais ampla.

Este artigo representa um esforço inicial de reflexão sobre uma relação pouco discutida até o momento. O caminho para a efetiva superação desse quadro, como vimos, envolve diversos aspectos e esferas, que vão desde a ampliação do campo de AP na academia e, especificamente na pós-graduação, até mudança de percepção dos administradores públicos e dos formuladores de políticas públicas para o setor. Há, portanto, uma gama de aspectos que precisam ser aprofundados em estudos futuros. Nesse sentido, esperamos que este artigo tenha contribuído para que os formuladores de políticas públicas ligados ao MEC e os responsáveis pelas construções das grades curriculares das IES na área da Administração possam olhar para o problema e incluí-lo em suas agendas. 


\section{Referências}

BANDEIRA DE MELLO, C. A. Curso de direito administrativo. São Paulo: Malheiros, 2012.

BOZEMAN, B. Public values and public interest: counterbalancing economic individualism. Washington, DC: Georgetown University Press, 2007.

BRESSER-PEREIRA, L. C. Desenvolvimento e crise no Brasil. São Paulo: Ed. 34, 2003.

CHILD, J. Fin del Estado. Bogotá: Grijalbo, 1993.

COELHO, F. S.; OLENSCKI, A. R. B.; CELSO, R. P. Da letargia ao realento: notas sobre o ensino de graduação em administração pública no Brasil no entremeio da crise do Estado e da redemocratização no país (1983-94). Rev. Adm. Pública, v. 45, n. 6, p. 1707-1732, 2011.

FERNANDES, F. A revolução burguesa no Brasil. Rio de Janeiro: Zahar, 1973.

FERNANDES, F. A integração do negro na sociedade de classes. Rio de Janeiro: Globo, 2009.

FISHER, T. A formação do administrador brasileiro na década de 90: crise, oportunidade e inovações nas propostas de ensino. Rev. Adm. Pública, v. 27, n. 4, p. 11-20, out./dez. 1993.

FONSECA, S. A.; COELHO, F. S. Panorama dos cursos de públicas no Brasil. Revista Temas de Administração Pública, v. 1, n. 6, Edição especial, 2010.

FURTADO, C. Formação econômica do Brasil. São Paulo: Companhia das Letras, 2009.

HOLANDA, S. B. Raízes do Brasil. São Paulo: Companhia das Letras, 1997.

IANNI, O. Estado e capitalismo no Brasil. São Paulo: Brasiliense, 1965.

INSTITUTO BRASILEIRO DE GEOGRAFIA E ESTATÍSTICA - IBGE. Sistemas de Contas Nacionais, ano referência - 2010. Rio de Janeiro: IBGE, 2015.

INSTITUTO NACIONAL DE ESTUDOS E PESQUISAS EDUCACIONAIS ANÍSIO TEIXEIRA - INEP. Censo da Educação Superior. Brasília, DF: 2013.

KETTL, D. A revolução global: reforma da administração do setor público. In: BRESSER-PEREIRA, L. C.; SPINK, P. (Org.). Reforma do Estado e administração pública gerencial. Rio de Janeiro: Ed. FGV, 2003. 75-122 p.

MONTEIRO, J. V. Maior complexidade institucional e poder de mando. Rev. Adm. Pública, v. 44, n. 4, p. 1023-1030, jul./ago. 2010.

NICOLINI, A. Qual será o futuro das fábricas de administradores? Revista de Administração de Empresas, v. 43, n. 2, p. 44-54, 2003.

OLIVEIRA, F. B.; SAUERBRONN, F. F. Trajetória, desafios e tendências no Ensino Superior de administração e administração pública no Brasil: uma breve contribuição. Rev. Adm. Pública, v. 41, n. Edição especial, p. 149-170, 2007.

PACHECO, R. Administração pública nas revistas especializadas: Brasil, 1995-2002. Revista de Administração de Empresas, v. 43, n. 4, p. 63-71, 2003.

PRADO JÚNIOR, C. A revolução brasileira. São Paulo: Brasiliense, 1978.

PRADO JÚNIOR, C. Formação do Brasil contemporâneo. São Paulo: Brasiliense, 1986. 
RIGGS, F. W. Administração nos países em desenvolvimento: a teoria da sociedade prismática. Rio de Janeiro: Ed. FGV, 1968.

SOROS, G. O novo paradigma para os mercados financeiros. Rio de Janeiro: Agir, 2008.

WERNECK SODRÉ, N. Formação histórica do Brasil. São Paulo: Difel, 1982.

WERNECK SODRÉ, N. Capitalismo e revolução burguesa no Brasil. Belo Horizonte: Oficina do Livro, 1990. 